\title{
Excess sensitivity of consumption to income growth: a model of Loss Aversion*
}

\section{Giacomo Pasini}

The article provides an empirical test on micro-data of a model of individual behavior based on Loss Aversion: utility is S-shaped, i.e. concave above reference consumption and convex below it. As a consequence individuals do not reduce current consumption in response to an expected income decline as long as uncertainty is high enough. Such a behavior is consistent with excess sensitivity of consumption to income growth, an empirical regularity which is hard to explain within a standard Life Cycle model. Loss Aversion is tested on an Italian dataset (the Bank of Italy's Survey on Households' Income and Wealth). The conclusion is that excess sensitivity could be explained by a model that do not assume individuals to be expected utility maximizers.

\section{Introduction}

Intertemporal consumption is one of the main topics in the econometric literature. Evidence is still quite controversial: as an example, while from a modeling point of view the Life Cycle/Permanent Income Hypothesis (PIH) of Modigliani and Friedman is generally accepted, this is not consistent with well-known empirical regularities as the positive and significant sensitivity of consumption growth to expected income growth. The PIH implies that individual income profile is humpshaped, consumption path is flat and they are uncorrelated. Nevertheless data exhibit a significant correlation between income and consumption series. Such an evidence is known as "excess sensitivity". Since Hall (1978), many authors tested several extensions of the PIH model in order to reconcile theory and evidence. Those extensions either allow for some characteristic of individual preferences not considered in the original PIH like prudence, or posit the presence of frictions in the market as credit constraints. All those models anyhow assume perfect rationality in the sense of Von Neumann and Morgenstern.

${ }^{\star}$ The first version of this article was written while visiting the Economics Department at Stanford University during my PhD. 
This is not the only approach to model individual preferences: Devetag (1999) and Aversi et al. (1999) modeled consumption decisions consistently with laboratory evidence provided by psychologists and experimental economists. In this article the possibility that excess sensitivity arises as a consequence of a behavior known as "Loss Aversion" is considered. While this is not the first attempt to run such a test on micro-data, the article contributes to the existing empirical literature explicitly taking into account the role of uncertainty in a Loss Aversion model, on the ground of the testable implications provided by Bowman et al. (1999) in a two period setting and extended to a life-cycle framework by Kószegi and Rabin (2006).

Section 2 discusses the implications of Loss Aversion on intertemporal consumption decisions and compare them to alternative explanations of excess sensitivity. Section 3 details the computation of income growth variables on the basis of a set of subjective expectations' questions. Fourth section is devoted to the estimation procedure and to the discussion of the results. Conclusions are in the last section.

\section{Loss Aversion in an intertemporal consumption model}

Loss Aversion is substantially an instance of reference dependence. People care more about losses relative to their reference point than about gains, and they exhibit riskadverse behavior in the domain of gains, while they are risk-lovers in the domain of losses. Such a behavior is assumed by the Prospect Theory developed by Kahneman and Tversky (1979) and Tversky and Kahneman (1992). Since it is an alternative to Expected Utility Theory, it is crucial to test it on individual data. In the last decades many authors found supporting evidence on laboratory experiments and using financial data, examples are Odean (1998) and Benartzi and Thaler (1995). One of the first attempts to test it on micro-data was Shea (1995), who found that using American data evidence is qualitatively consistent with Loss Aversion. Garcia et al. (1997) still found supporting evidence, but only among individuals that are not liquidity constrained. Empirical evidence is not all in favor of Loss Aversion: Jappelli and Pistaferri (2000) used an Italian survey and after controlling for prudence they found no significant effect of Loss Aversion.

The aim of this section is to set up an encompassing model which can be used to test simultaneously the standard $\mathrm{PIH}$, prudence, liquidity constraints, and Loss Aversion. The starting point is the main insight of Hall (1978), which is that under the $\mathrm{PIH}$ consumption follows a martingale, i.e. changes in consumption between time $t$ and $t+1$ should be uncorrelated with any information in the consumers' information set at time $t$. Such a result can be formalized as

$$
\Delta \ln C_{i, t+1}=\boldsymbol{\beta}_{\mathbf{1}} \boldsymbol{X}_{\boldsymbol{i}, \boldsymbol{t}+\mathbf{1}}+\epsilon_{i, t+1}
$$


where $\boldsymbol{X}_{\boldsymbol{i}, \boldsymbol{t}+\boldsymbol{1}}$ is a vector of demographic characteristics accounting for differences in individual preferences. ${ }^{1}$ If leisure and consumption are not separable, proxies for labor market conditions in $\boldsymbol{X}_{\boldsymbol{i}, \boldsymbol{t}+\mathbf{1}}$ are endogenous, and must be instrumented. Equation (1) is the empirical counterpart of the Euler equation arising from the firstorder conditions of the intertemporal maximization problem:

$$
\mathrm{E}\left[U^{\prime}\left(C_{t}\right) \mid I_{0}\right]=U^{\prime}\left(C_{0}\right), t=1, \ldots, T
$$

The martingale property of consumption holds as it is stated in (1) only under a number of important assumptions. Relaxing some of them, a generalized version of (1) can account for several (and potentially competing) explanations of empirical regularities, such as the excess sensitivity of consumption to income growth.

The first assumption to be relaxed is somewhat hidden. If the individual utility function is not linear, so even for a Constant Relative Risk Aversion (CRRA) utility, equation (1) is a first-order approximation of the true Euler equation (2). Using a second-order Taylor expansion it is clear that second and higher order moments of $\Delta \ln C_{i, t+1}$ must be orthogonal to variables in the information set at time $t$ in order not to appear in the right-hand side of equation (1). Jappelli and Pistaferri (2000) and Dynan (1993) relax this assumption: they show that if the utility function is at least three times differentiable, consumption growth depends on its variance: ${ }^{2}$

$$
\Delta \ln C_{i, t+1}=\boldsymbol{X}_{\boldsymbol{i}, \boldsymbol{t}+\mathbf{1}} \boldsymbol{\beta}_{\mathbf{1}}+\beta_{2} \operatorname{Var}\left[\Delta \ln C_{i, t+1}\right]+\epsilon_{i, t+1}
$$

$\beta_{2}$ is then an affine transformation of the coefficient of relative prudence, defined by Blanchard and Mankiw (1988) as $r=-C\left(U^{\prime \prime \prime} / U^{\prime \prime}\right)$. Even if this assumption involves the order of the Taylor approximation and a third derivative of utility, this is not simply technical: a prudent consumer takes uncertainty into account when facing the intertemporal consumption planning problem, while a PIH one does not. A PIH maximizer facing an expected increasing path of income would rise current consumption and reduce the future one in order to smooth its life-cycle profile. A prudent individual instead would do the same only if the expected income is "sure", i.e. if there is no uncertainty. Vice versa, a high level of volatility would induce the prudent consumer to keep current consumption low and save. Therefore, if income actually increases, future consumption would track it, generating an excess sensitivity of consumption to income growth. A test for prudence against standard $\mathrm{PIH}$ is then a test of $\beta_{2}$ significance.

\footnotetext{
${ }^{1}$ Changes in consumption between periods is measured as the difference in natural logarithms: $\Delta \ln C_{t+1}=\ln C_{t+1}-\ln C_{t}$ (the $i$ subscript is dropped just for exposition clearness). As it is common in the consumption literature, this is taken as an approximation of the growth rate of consumption: $\Delta \ln C_{t+1} \simeq\left(C_{t+1}-C_{t}\right) /\left(C_{t}\right)$. Thus, in the remaining of the article changes in consumption and consumption growth rate are used as synonyms. The same assumption applies to the growth rate of income and of other variables used in the analysis.

${ }^{2}$ The same result can be derived with a exponential utility function and an Autoregressive Moving Average (ARMA) process generating income (Caballero, 1990).
} 
The martingale property (1) is obtained assuming that capital markets are perfect, in the sense that individuals can transfer any desired amount of money from one period to another. Suppose instead that consumers are perfectly rational, they maximize their utility as under PIH (with or without prudence), but they are liquidity constrained, i.e. they cannot borrow against future income forcing current consumption to be below current resources. When agents expect future income to increase and the constraint is binding, they cannot smooth consumption: consumption growth is sensitive to income growth. On the other hand, an expected income decline would induce to reduce current consumption in order to smooth it: saving in order to transfer resources to future periods is not affected by liquidity constraints. The empirical implication is that there is an asymmetry in the sensitivity of consumption changes to predicted income changes: for a liquidity constrained individual consumption growth is sensitive to an income increase, but not to an income decline. Equation (3) is therefore augmented:

$$
\begin{aligned}
\Delta \ln C_{i, t+1}= & X_{i, \boldsymbol{t}+\mathbf{1}} \boldsymbol{\beta}_{1}+\beta_{2} \operatorname{Var}\left[\Delta \ln C_{i, t+1}\right] \\
& +\beta_{3} \Delta \ln \mathrm{E}[Y]_{i, t+1}^{+}+\beta_{4} \Delta \ln \mathrm{E}[Y]_{i, t+1}^{-}+\epsilon_{i, t+1}
\end{aligned}
$$

where

$$
\begin{aligned}
\Delta \ln \mathrm{E}[Y]_{i, t+1}^{+} & =I_{(\Delta)} \Delta \ln \mathrm{E}[Y]_{i, t+1} \\
\Delta \ln \mathrm{E}[Y]_{i, t+1}^{-} & =\left(1-I_{(\Delta)}\right) \Delta \ln \mathrm{E}[Y]_{i, t+1} \\
\Delta \ln \mathrm{E}[Y]_{i, t+1} & =\ln \mathrm{E}[Y]_{i, t+1}-\ln Y_{i, t} \\
I_{(\Delta)} & = \begin{cases}\Delta \ln \mathrm{E}[Y]_{i, t+1} & \text { if } \Delta \ln \mathrm{E}[Y]_{i, t+1}>0 \\
0 & \text { otherwise }\end{cases}
\end{aligned}
$$

A test for the presence of liquidity constraints is then $H_{0, L C}: \beta_{3}>0$ and $\beta_{4}=0$ in (4).

The third assumption to be relaxed, even allowing both for prudence and liquidity constraints, is that individuals are expected utility maximizers. Loss Aversion allows for reference dependence and risk loving behavior in the domain of losses. Reference dependence means that individuals do not enjoy a consumption level per se, but its distance from a target consumption level. The reference consumption level is usually thought to be the status quo level, i.e. the consumption schedule individuals are accustomed to. The second characteristic of Loss Aversion is an asymmetry between consumption above and below the reference level: individuals are risk averse in the domain of gains (where a "gain" in this setting is consuming above the reference level) and risk-seekers in the domain of losses. As an example, take an exponential function piecewise continuous:

$$
U(x)= \begin{cases}-2 e^{-\frac{1}{2} x}+2 & \text { if } x>0 \\ 5 e^{-\frac{1}{5} x}+5 & \text { if } x \leq 0\end{cases}
$$




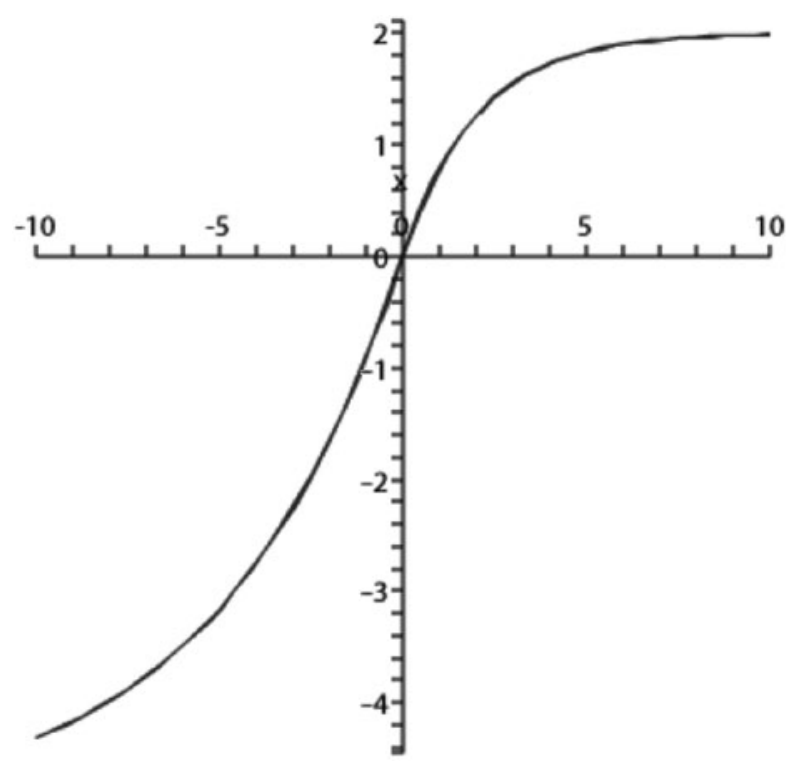

Figure 1 S-shaped utility function.

where $x$ is the difference between current consumption and the reference level, set to 0 in this example. $U(x)$ is always increasing, it changes curvature in 0 (i.e. at the reference point), below the reference point is convex and above is concave and less steep (Figure 1).

Such an utility function captures a loss-averse behavior: the marginal disutility of a loss is higher than the marginal utility of a comparable gain. The formal model we refer to is the one developed by Bowman et al. (1999) in a two-period setting. A detailed description of its features can be found in the appendix, while this section focuses on its implication for intertemporal consumption decision. The central result of Bowman et al. (1999) is that when there is enough uncertainty, people resist lowering consumption in response to an expected income decline. This result comes from the risk-seeking behavior in the domain of losses: individuals are willing to pay in order to give up a certain loss today for an uncertain one tomorrow. Since with uncertainty there is a chance that future income will not reduce, they prefer to keep consumption above the reference point today and bear the risk of suffering a bigger loss tomorrow. Such a result is valid even if there are no chances of consuming above the reference level in any of the two periods: uncertainty still leaves a positive probability of suffering a smaller loss tomorrow than the certain one today. Bowman et al. (1999) model is developed in a two-period setting, but the result is maintained in a multi-period model if the reference consumption level does not change along time: if uncertainty is high enough, people tend to 
postpone losses. ${ }^{3}$ In terms of empirical implication this means that, given a sufficiently high uncertainty level, consumers resist to lower immediately consumption in response to an expected income decline.

Retrieving a clear implication about consumers' response to an expected income growth is less straightforward. Depending on the individual utility function, an agent could behave as a PIH maximizer and increase consumption in both periods, or he could maintain consumption at the reference point in the first period in order to enjoy a higher gain in the second period. Thus, the marginal effect of an actual income increase can be either significant or not. Something can be said about the relative magnitude of an income decline and an income increase effect: Bowman et al. (1999) assume that the S-shaped utility function is steeper in the domain of losses than it is in the domain of gains (as it is the function in Figure 1). Therefore, given such an utility function the marginal effect of a gain is smaller than the marginal effect of a comparable loss. We can formalize those implications generalizing (4) again:

$$
\begin{aligned}
\Delta \ln C_{i, t+1}= & \boldsymbol{\beta}_{1}{ }^{\prime} \boldsymbol{X}_{\boldsymbol{i}, \boldsymbol{t}}+\beta_{2} \operatorname{Var}\left[\Delta \ln C_{i, t+1}\right] \\
& +\beta_{3} \Delta \ln \mathrm{E}[Y]_{i, t+1}^{+}+\beta_{4} \Delta \ln \mathrm{E}[Y]_{i, t+1}^{-} \\
& +\beta_{5}\left(\Delta \ln \mathrm{E}[Y]_{i, t+1}^{+} \times \operatorname{Var}\left[\Delta \ln C_{i, t+1}\right]\right) \\
& +\beta_{6}\left(\Delta \ln \mathrm{E}[Y]_{i, t+1}^{-} \times \operatorname{Var}\left[\Delta \ln C_{i, t+1}\right]\right)+\epsilon_{i, t+1}
\end{aligned}
$$

It should be remarked that (9) is not the equivalent of Euler equation obtained from a model accounting for prudence, liquidity constraints, and Loss Aversion. It is an augment version of the standard Euler equation used to highlight an empirical relation between consumption and income growth rates, and to test the implications on such a relation of different economic models. Back to Loss Aversion, the first implication is that for a high enough uncertainty, the marginal effect of an income decline is positive. Thus, consumption variance augment the sensitivity of the growth rate of consumption to predicted income declines:

$$
H_{0,1}: \beta_{6}>0
$$

In order to test the other implications marginal effects must be computed:

$$
\begin{aligned}
& \varphi^{-}=\frac{\partial \Delta \ln C}{\partial \Delta \mathrm{E}[Y]^{-}}=\beta_{4}+\beta_{6} \operatorname{Var}\left[\Delta \ln C_{i, t+1}\right] \\
& \varphi^{+}=\frac{\partial \Delta \ln C}{\partial \Delta \mathrm{E}[Y]^{+}}=\beta_{3}+\beta_{5} \operatorname{Var}\left[\Delta \ln C_{i, t+1}\right]
\end{aligned}
$$

\footnotetext{
${ }^{3}$ See the appendix for the exact set of assumptions needed to extend the model to a multi-period setting.
} 
Table 1 Testable implications

\begin{tabular}{llll}
\hline $\mathrm{PIH}$ & Prudence & Liquidity constraints & Loss Aversion \\
\hline$\frac{\partial \Delta \operatorname{In} C}{\partial V \operatorname{ar}[\Delta \ln C]}=0$ & $\frac{\partial \Delta \operatorname{In} C}{\partial \operatorname{Var}[\Delta \ln C]}>0$ & $\varphi^{+} \geq 0$ & $\beta_{6}>0$ \\
$\varphi^{+}=\varphi^{-}=0$ & $\varphi^{+}=\varphi^{-}=0$ & $\varphi^{-}=0$ & $\varphi^{+}<\varphi^{-}$ \\
\hline
\end{tabular}

If the null $H_{0,1}$ holds, then $\varphi^{-}$is expected to be statistically significant only for high values of $\operatorname{Var}\left[\Delta \ln C_{i, t+1}\right]$. Moreover, if the utility function is steeper in the domain of losses rather than in the domain of gains, the marginal effect of a predicted income decline must be larger than the marginal effect of an income increase:

$$
H_{0,2}: \varphi^{-}>\varphi^{+}
$$

Bowman et al. (1999) show that in this model an increase in uncertainty can either increase or decrease consumption. What can be shown is that if expected income is slightly below the reference level, an increase in uncertainty will increase consumption growth. The explanation is similar to the previous one: an expected income decline puts the agent in the domain of losses. An increase in uncertainty will rise the chances that agents will be able to consume above the reference level in both periods, and therefore they will be more reluctant to reduce current consumption. Again, maintaining a higher consumption in the first period will lead to a bigger reduction in the second period if actual income eventually falls. Thus, since individual reference consumption is typically unknown, it is not possible to retrieve a clear-cut implication on the variance's marginal effect.

Table 1 summarizes the implications described in this section referring to equation (9) parameters. Note that since the interaction terms not involved in (3) appear in (9), tests for prudence must be rewritten in terms of marginal effects.

\section{Specification issues}

In order to consistently estimate (11) it is necessary to tackle a number of econometric issues. First, as already stated in the previous section, consumption and labor market decision are likely not to be separable. If this is the case, working hours and expected income are almost surely correlated, thus it is necessary to include among the regressors $\boldsymbol{X}_{\boldsymbol{i}, \boldsymbol{t}}$ an exogenous proxy for labor supply. Following Jappelli and Pistaferri (2000) a dummy indicating the lagged working status of the spouse is used.

The second issue is that the disturbance term $\epsilon_{i, t}$ in (9) is a forecast error, the difference between realized and expected consumption growth. According to any model presented before, the time $t$ expectation of the forecast error is zero. This posit a problem on estimation with short panels: $E\left[\epsilon_{i, t}\right]$ converges towards zero as $t$ goes to 
infinity, but this do not guarantee that the cross-sectional average goes to zero even for large $N$. In particular, aggregate shocks may induce cross-sectional correlation between expected consumption growth and income growth that does not go to zero as $N$ increases. In order to account for unevenly distributed exogenous shocks, the error term includes a year dummy and its interaction with a set of demographics:

$$
\begin{aligned}
\Delta \ln C_{i, t+1}= & \boldsymbol{\beta}_{1}{ }^{\prime} \boldsymbol{X}_{\boldsymbol{i}, \boldsymbol{t}}+\beta_{2} \operatorname{Var}_{\boldsymbol{t}}\left[\Delta \ln C_{i, t+1}\right] \\
& +\beta_{3} \Delta \ln \mathrm{E}[Y]_{i, t+1}^{+}+\beta_{4} \Delta \ln \mathrm{E}[Y]_{i, t+1}^{-} \\
& +\beta_{5}\left(\Delta \ln \mathrm{E}[Y]_{i, t+1}^{+} \times \operatorname{Var}\left[\Delta \ln C_{i, t+1}\right]\right) \\
& +\beta_{6}\left(\Delta \ln \mathrm{E}[Y]_{i, t+1}^{-} \times \operatorname{Var}\left[\Delta \ln C_{i, t+1}\right]\right) \\
& +\left(\mu_{\boldsymbol{t}+\mathbf{1}}{ }^{\prime} \boldsymbol{\theta}+u_{i, t+1}\right)
\end{aligned}
$$

The time $t$ conditional variance included in (14) is crucial both to test for prudence and Loss Aversion, but it is often excluded from the estimation since it is not trivial to find a suitable proxy for it. Consumption variance is clearly correlated with income variance, but it may well depend on other uncertainty sources: health risk, interest rates and therefore return on assets' volatility, inflation risk. The dataset on which the estimation will be carried on is an Italian survey: given the extensive public health insurance in Italy, the role of health risk in determining consumption volatility is likely to be negligible compared with income variance. Returns on assets and inflation volatility are potentially more relevant. Nevertheless, the error term structure account for aggregate shocks which are likely to affect any financial return together with expected consumption and wages. Thus, it is reasonable to assume that income variance is a good proxy for consumption variance. Hence, in what follows, $\operatorname{Var}_{t}\left[\Delta \ln C_{i, t+1}\right]$ is proxied by $\operatorname{Var}_{t}\left[\Delta \ln Y_{i, t+1}\right]$ where the latter is obtained directly from subjective expectations.

\subsection{Subjective expectations}

The usual way to deal with Euler equation is to estimate a regression of consumption growth on actual income growth. Actual income growth is not exogenous: it involves time $t+1$ income which is not known to the consumer at time $t$, and both consumption and income depend on unobservable individual characteristics. Therefore if leisure and consumption are not separable they are simultaneously determined. Thus it is crucial to account for endogeneity, finding a suitable instrument for actual income growth or a direct measure of expected income.

The dataset at hand come from the Survey on Households' Income and Wealth (SHIW) run by the Italian Central Bank. This survey has the advantage of including subjective expectations about future income. The measure that can be obtained from these questions is the "perfect" instrument, since by construction it is included in the consumers' information set at time $t$ and thus it is not correlated with the error term. 
Observations are taken from the year 1995, 1998, and 2000 waves from SHIW. In 1995 and 1998, the survey included the following questions about expected income:

- $p_{i}$ : What is the probability that in 1 year time you will be employed?

- $\underline{Y}_{i, t}$ : Given that in 1 year time you will be employed, what is the minimum earning that you expect?

- $\bar{Y}_{i, t}$ : And what is the maximum?

- $q_{i}$ : What is the probability you will earn less than $(\underline{Y}+\bar{Y}) / 2$ ?

These questions were asked only to a subsample of individuals among employees, self employed or unemployed looking for their first employment. Only household heads are included since the quality of the data for other household members is generally poor. Therefore, a "valid" observation is a household head with the following characteristics:

1. interviewed at least in two consecutive waves among 1995, 1998, and 2000;

2. answered to the subjective questions; and

3. did not change status of household head between the two waves.

What is left are 1447 observations, 623 from the 1995/1998 period and the remaining 824 from 1998/2000.

\subsection{Expected income variables}

In each year $t$, income $Y_{i, t}$ refers to the particular subsample at hand. Therefore it is earnings from labor as defined in the national accounts, i.e. the sum of wages and earnings from self employment. In contrast to Guiso et al. (2002), unemployment benefit or pensions are not considered, hence strictly speaking $Y_{i, t}$ is earnings from labor, not income. Observations with $Y_{i, t}$ equal to 0 were replaced with 1 , in order not to exclude unemployed.

Pooling data from different waves inflation must be taken into account: monetary measures are all expressed in 1995 thousands of Italian lires by means of the annual consumption price index provided by ISTAT (the Italian National Statistics Bureau).

Expected income depends on the probability of being employed $p$ :

$$
Y_{i, t}= \begin{cases}\omega_{i, t} & \text { with probability } p_{i, t} \\ 0 & \text { with probability } 1-p_{i, t}\end{cases}
$$

where $\omega_{i}$ are earnings from employment. As in Guiso et al. (2002), $\omega$ is assumed to follow a triangular distribution in order to use all the available subjective information: ${ }^{4}$

$$
\begin{aligned}
& \mathrm{E}[Y]=p \mathrm{E}[\omega] \\
& \text { where } \mathrm{E}[\omega]=\frac{1}{3}(q(2 \underline{Y}+\bar{Y})+(1-q) \times(\underline{Y}+2 \bar{Y}))
\end{aligned}
$$

\footnotetext{
${ }^{4}$ Subscripts are omitted.
} 
$\mathrm{E}[\omega]$ is the expected value of the triangular distribution. The difference between $\mathrm{E}[Y]$ 's logarithmic transformation and current log income is used as an approximation of income growth between times $t$ and $t+1$. Finally, based on the sign of such a measure expected income increase $\Delta \ln \mathrm{E}[Y]_{i, t+1}^{+}$and decline $\Delta \ln \mathrm{E}[Y]_{i, t+1}^{-}$are obtained. The same set of subjective questions allows to build an individual measure of expected income variance:

$$
\begin{aligned}
\operatorname{Var}[Y]=p \operatorname{Var}[\omega]+p & (1-p) \mathrm{E}[\omega]^{2} \\
\text { where } \operatorname{Var}[\omega]= & \frac{1}{24}\left(q\left(11 \underline{Y}^{2}+10 \underline{Y} \bar{Y}+3 \bar{Y}^{2}\right)\right. \\
& \left.+(1-q)\left(3 \underline{Y}^{2}+10 \underline{Y} \bar{y}+11 \bar{Y}^{2}\right)\right)-\mathrm{E}[\omega]^{2}
\end{aligned}
$$

Again, $\operatorname{Var}[\omega]$ is the second central moment of a triangular distribution. Via a logarithmic approximation coherent with what is done for $\Delta \ln \mathrm{E}[Y]_{i, t+1}$, income variance and current income are enough to obtain a measure of the variance of expected income growth:

$$
\operatorname{Var}_{t}\left[\Delta \ln \mathrm{E}[Y]_{i, t+1}\right] \simeq \frac{\operatorname{Var}_{t}\left[Y_{i, t+1}\right]}{Y_{i, t}^{2}}
$$

This is then used as a measure for the variance of consumption growth, $\operatorname{Var}\left[\Delta \ln C_{i, t+1}\right]$, given the assumption stated at the end of the previous section.

\section{Estimation and results}

The first approach is to use those measures to estimate (14) with ordinary least squares (Appendix Table B1): expected income increase, decline, and variance computed using subjective expectations are all in the information set at time $t$, and thus no endogeneity problem arises. Regardless of the specification, even if the signs and relative magnitude of income increase and income decline parameters' estimates are consistent with Loss Aversion, they are not significant thus supporting the PIH without prudence. In other words, there is no significant evidence of excess sensitivity of consumption to income growth. This result is not in line with previous literature and with well-established empirical evidence: a deeper analysis of the estimation method is needed.

Poor significance is likely to arise from the choice of income growth measure. Subjective questions are about income in 1-year time, while the survey is done every 2 or 3 years. Moreover, the expectations do not refer to the first year in the interval between the survey. SHIW interviews usually start in the first months of the year, and household are asked about income of the previous calendar year. Therefore, since subjective expectations refer to a 1-year ahead starting from the moment of the interview, the relevant time spell depends on the actual date of the interview, which is not a publicly available information. Table 2 summarizes the time horizon of actual 
Table 2 Time horizons

\begin{tabular}{lll}
\hline $\begin{array}{l}\text { Households } \\
\text { interviewed in: }\end{array}$ & $\begin{array}{l}\text { Actual income growth } \\
\text { actual consumption growth }\end{array}$ & Subjective expectations \\
\hline 1995 and 1998 & from Jan 1995 to Dec 1997 & from May/Sept 1996 to Apr/Aug 1997 \\
1998 and 2000 & from Jan 1998 to Dec 1999 & from Feb/Jul 1999 to Jan/June 2000 \\
\hline
\end{tabular}

income and consumption growth, compared with the one referring to subjective expectations.

If agents actually plan their consumption with a 2- or 3-year horizon this fact does not generate any problem, since the 1-year expectation can be considered a good proxy for a 3-year expectation. By the way such a planning horizon seems too long. It is reasonable to think that households review their consumption decision every year: Benartzi and Thaler (1995) found evidence which can be explained by such a planning horizon for investment decisions. Their argument is that since income taxes are payed once a year in that period families are forced to think about their earnings and investments; that is also the moment in which they review their asset allocation.

Given the data at hand, 1-year ahead subjective expectations can be considered a good measure for expectations over the actual interval between surveys only if individuals expect their income to grow uniformly. Jappelli and Pistaferri (2000) show that while 1-year expectation is a good predictor of actual income growth over a longer horizon, the uniform growth assumption is too strong. Thus, as it is standard in the intertemporal consumption literature, we use actual income growth as a proxy for expected income growth over the relevant periods. As it was explained in the previous section, actual income is endogenous since it is built using information that are not in the information set of individuals at time $t$. We then estimate (14) with two-stage least squares, using 1-year ahead expectations as instruments. The same reasoning should go through for expected income variance: it refers to 1-year ahead income expectation, and therefore it suffers same problems of 1-year expected income growth. Unfortunately it cannot be treated in the same way: expected income growth is used as an instrument for 3-year actual income growth, while it is not possible to have a measure of the actual individual variance, nor a better measure of expected 3-year ahead expected variance. Given these data limitations, in the present article expected income variance is plugged directly in the regression, avoiding the endogeneity problem of actual measures. The drawback is clearly that a 1-year ahead expectation is used as a proxy for a 3 -year expectation. ${ }^{5}$

\footnotetext{
${ }^{5}$ Bertola et al. (2005) follow an alternative approach: using the same Italian survey, the authors proxy actual income variance with the squared actual income growth, and then they treat it as an
} 
In the first stage, actual income growth is regressed on 1-year expectation and all the other exogenous regressors. Results are reported in Appendix Table B2. Many households were interviewed both in 1995 and in 1998, so they appear twice in the sample. Clearly, those observations cannot be assumed to be uncorrelated: robust standard errors' estimation takes into account those variability clusters. First stage estimates provide a test of the structure of the error term: if there is heterogeneity on the effect of aggregate shocks, the interactions of group variables with the year dummies should be significant. As described in Section 3, the error term has the following structure:

$$
\epsilon_{i, t+1}=\boldsymbol{\mu}_{t+1}^{\prime} \boldsymbol{\theta}+u_{i, t+1}
$$

$\boldsymbol{\mu}_{t+1}$ are interactions between year effect and group dummies, and they capture unevenly distributed exogenous shocks. They are jointly significant (a joint F-test is rejected at any confidence level), some are also individually significant, thus supporting the assumption that aggregated shocks have different effects on different groups.

Second stage results are reported in Appendix Table B3. Such an estimation is not straightforward, at least in column (2) and (3): expected income increase, decline, and their interaction with expected income variance are non-linear transformations of the first stage predicted value. Being more specific, the predicted value of the first stage designs either a predicted income increase or decline depending on its sign. The asymptotic distribution of estimated coefficients is therefore unknown: in order not to do explicit assumptions on their distribution, standard errors and $P$-values are bootstrapped. $^{6}$

As for the Ordinary Least Squares (OLS) estimates, column (1) and (2) of Appendix Table B3 support the PIH. The third column, which report the estimation results for the complete regression (14), provides evidence in favor of Loss Aversion: the parameter of the interaction between expected variance and expected income decline is positive and significant, thus the null hypothesis $H_{0,1}: \beta_{6}>0$, reported in (10) is accepted.

Appendix Table B4 reports the marginal effects of expected income increase and decline, the test statistics for $H_{0,2}: \varphi^{-}>\varphi^{+}$and its standard error, obtained taking into account the correlation between $\varphi^{+}$and $\varphi^{-}$. They are computed at various percentiles of expected income variance's distribution: $\varphi^{+}$is never

endogenous regressor to be instrumented with expected income variance. As a robustness check the same procedure has been applied to the present setting: results differ from the reported estimates and evidence in favor of Loss Aversion is reduced. It must be noted anyway that the first stage results highlight a poor explanatory power of expected income and variance: instruments are exogenous but weak for squared actual income growth.

${ }^{6}$ While not correct due to the definition of predicted income increase and decline, the usual robust standard errors for the second stage have been computed. Results, in terms of significance of the key regressors, are unchanged. Moreover, their magnitude is comparable with bootstrap standard errors. 
statistically significant, while $\varphi^{-}$is significant only above the $85^{\text {th }}$ percentile of variance distribution. $H_{0,2}$ is accepted only for high values of variance as well: as predicted by the model, expected income decline has a positive marginal effect on consumption growth only with high uncertainty. When such an effect is statistically relevant, it is significantly larger than the corresponding marginal effect for expected income increase.

These results, even if already supportive of the Loss Aversion model, are potentially underestimates of the true effect of expected income decline: expected income variance is extremely low (its median is close to zero) and its marginal effect is never significant. Such a result may be due to the fact that variance of 1 -year ahead expected income is used as a proxy for $2 / 3$ year ahead variability, which is likely to be higher. Moreover, a low level of uncertainty about future income is reasonable for Italy: given the well-known rigidity of the Italian labor market, in particular the tight bounds to layoffs and the low number of job-to-job movement at older ages, unemployment risk is likely not to be relevant. Further evidence in this sense comes from the fact that the instrument for labor market conditions is not significant: if the instrument is valid this means either that leisure and consumption are separable, which is in contrast with previous labor economic literature, or simply that there is almost no unemployment in the sample. Descriptive statistics confirm this second possible conclusion: out of 1447 observations only 59 are unemployed.

\section{Conclusions}

This article puts together two strands of literature. On one side, the experimental economics evidence against Expected Utility Theory in laboratory experiments. The axioms at the basis of the Von Neumann-Morgenstern theory were tested and rejected, and alternative behavioral models were proposed. Among them, the Prospect Theory of Kahneman and Tversky (1979) has a prominent role and seems to fit experimental evidence about the decision process of the individuals. As an example, it is able to deal with Loss Aversion, the fact that people have different attitudes towards gains or losses.

On the other side, micro-econometricians proposed different explanations of the excess sensitivity of consumption growth to expected income. These models allow for individual heterogeneity and are estimated on survey data. Nevertheless all these models rely on the basic assumption that agents are expected utility maximizers. Here, the proposed explanation of excess sensitivity is an estimable version of Prospect Theory that allows for Loss Aversion. A two-period model is set up and the testable implications derived. The model is consistent with the data: from a behavioral point of view, this is amongst the first attempts to test carefully Loss Aversion on micro-data. From an econometric point of view, the model accounts for excess sensitivity at least as well as other extensions to PIH do. 
Due to the stark differences on the assumptions about individual preferences between the Life Cycle/PIH and Prospect Theory/Loss Aversion, the natural extension of what is proposed in this article is to fully understand the intertemporal implications of Loss Aversion. This not an easy task: relaxing the perfect rationality assumption has the drawback that obtaining closed form solutions as the Euler equation turns out to be extremely difficult. Nevertheless the payoff for such an effort could be quite high: the goal is to describe correctly individual behavior under uncertainty, a building block of microeconomics.

\section{Acknowledgements}

I wish to thank Luigi Pistaferri, Massimo Warglien, Enrico Rubaltelli, and two anonymous referees for helpful comments.

\section{Address for correspondence}

Giacomo Pasini, Utrecht School of Economics, Janskerkhof 12, 3512 BL Utrecht, Netherlands. e-mail: g.pasini@econ.uu.nl

\section{References}

Aversi, R., G. Dosi, G. Fagiolo, M. Meacci and C. Olivetti (1999), 'Demand dynamics with socially evolving preferences,' Industrial and Corporate Change, 8(2), 353-408.

Benartzi, S. and R. H. Thaler (1995), 'Myopic loss aversion and the equity premium puzzle,' Quarterly Journal of Economics, 110(1), 73-92.

Bertola, G., L. Guiso and L. Pistaferri (2005), 'Uncertainty and consumer durables adjustment,' Review of Economic Studies, 72(4), 973-1007.

Blanchard, O. J. and G. Mankiw (1988), 'Consumption: beyond certainty equivalence,' American Economic Review, 78(2), 173-177.

Bowman, D., D. Minehart and M. Rabin (1999), 'Loss aversion in a consumption-savings model,' Journal of Economic Behavior \& Organization, 38, 155-179.

Caballero, R. J. (1990), 'Consumption puzzles and precautionary savings,' Journal of Monetary Economics, 25(1), 113-136.

Devetag, M. G. (1999), 'From utilities to mental models: a critical survey on decision rules and cognition in consumer choice,' Industrial and Corporate Change, 8(2), 289-351.

Dynan, K. (1993), 'How prudent are consumers?', Journal of Political Economy, 101(6), 1104-1113.

Garcia, R., A. Lusardi and S. Ng (1997), 'Excess sensitivity and asymmetries in consumption: an empirical investigation,' Journal of Money, Credit and Banking, 29(2), 154-176.

Guiso, L., T. Jappelli and L. Pistaferri (2002), 'An empirical analysis of earnings and employment risk,' Journal of Business \& Economic Statistics, 20(2), 241-253. 
Hall, R. H. (1978), 'Stochastic implications of the life cycle-permanent income hypothesis: theory and evidence,' The Journal of Political Economy, 86(6), 971-987.

Jappelli, T. and L. Pistaferri (2000), 'Using subjective income expectations to test the excess sensitivity of consumption to predicted income changes,' European Economic Review, 44, $337-358$.

Kahneman, D. and A. Tversky (1979), 'Prospect theory: an analysis of decision under risk,' Econometrica, 47, 263-291.

Kószegi, B. and M. Rabin (2006), 'A model of reference-dependent preferences,' The Quarterly Journal of Economics, 121(4), 1133-1165.

Odean, T. (1998), 'Are investors reluctant to realize their losses?', Journal of Finance, 8(5), $1776-1798$.

Shea, J. (1995), 'Union contracts and the life cycle/permanent income hypothesis,' American Economic Review, 85(1), 186-200.

Tversky, A. and D. Kahneman (1992), 'Advances in prospect theory: cumulative representation of uncertainty,' Journal of Risk and Uncertainty, 5, 297-323.

\section{Appendix A}

\section{Bowman et al. (1999) model and extensions}

This appendix reviews Bowman et al. (1999): the authors propose a two-period consumption model that allows to separate the reference dependence from the gainloss utility to the original assumptions of Kahneman and Tversky (1979):

$$
U(r, c)=w(r)+v(c-r)
$$

where $c$ is the consumption level, $r$ the reference level of consumption, $w(x)$ is the reference utility, which captures the utility dependence from the reference point given the distance of consumption level from it. $v(x)$ is the gain-loss value function. Assumptions are:

1. $v(0)=0$;

2. $v^{\prime}(x)>0$;

3. $v^{\prime}(y)>2 v^{\prime}(x),{ }^{7}$ where $x>0, y<0, \quad|x|=|y|$, i.e. the marginal value of a loss is at least twice as big as the marginal value of a comparable gain;

4. $v(x)$ is strictly concave for $x>0$ (risk-aversion) and strictly convex for $x<0$ (risk-love).

\footnotetext{
${ }^{7}$ Kahneman and Tversky (1979) found experimentally that the ratio of Loss Aversion—marginal utility of losses divided by marginal utility of gains-is about 2.5 . Bowman et al. prove most of their results also under alternative (but somewhat less natural) assumptions.
} 
5. $(\partial U(r, c)) /(\partial r)<0$ utility is decreasing in the reference level. In other words, a person derives more satisfaction from a fixed level of consumption the lower the reference point.

Without loss of generality, Bowman et al. (1999) assume also $v(x), w(x)$ to be continuous, with bounded slope and twice differentiable but for $c=r$. The gain-loss value function $v(\cdot)$ is then $\mathrm{S}$-shaped. Writing the consumer optimization problem in a two-periods world is straightforward:

$$
\begin{gathered}
U\left(r_{t}, c_{t} ; r_{1}, c_{1} \mid I_{1}\right)=w\left(r_{1}\right)+v\left(c_{1}-r_{1}\right)+\mathrm{E}\left[w\left(r_{2}\right)+v\left(c_{2}-r_{2}\right) \mid I_{1}\right] \\
\text { subject to } c_{2}=\left(Y_{1}-c_{1}\right)+Y_{2} \\
r_{2}=(1-\alpha) r_{1}+\alpha c_{1}
\end{gathered}
$$

All the uncertainty is in future income, $Y_{2}$. The second constraint is a hypothesis on habit formation, where $\alpha$ is the rate at which reference point adjust to recent consumption. The main result of Bowman et al. (1999), invoked in Section 2 is the following:

$$
\begin{aligned}
& \text { if } P\left[\frac{Y_{1}+Y_{2}}{2} \geq r_{1}\right] \geq \frac{2 \alpha}{1+\alpha} \\
& \text { then } P\left[\frac{Y_{1}+Y_{2}}{2} \geq \frac{1}{2} r_{1}\right]=1 \Longrightarrow c_{1} \geq r_{1}
\end{aligned}
$$

With Loss Aversion, if uncertainty is over a threshold determined by the reference level, agents resist to reduce their current consumption in response to an expected income decline. This result comes from the risk-seeking behavior in the domain of losses: with uncertainty there is a chance that future income will not reduce, so that the agent can maintain a higher standard of living (i.e. a higher reference level). The lower the parameter $\alpha$, the higher the relevance of the reference point of period 1 and therefore the incentive to postpone losses. If $\alpha=0$, the reference point do not change as a consequence of consumption decision of the individuals, i.e. it is exogenous. In this case consumers will postpone losses as long as their expected average income allows to do so, i.e. as long as they respect the intertemporal budget constraint.

Bowman et al. (1999) briefly discuss the intertemporal extension of their model. Even if the discontinuity at the reference point do not allow for a straightforward characterization of Loss Aversion implications in such a setting, restricting to $\alpha=0$ allows to have an intertemporally separable utility function, and thus (21) is still valid. This is equivalent to assume that the reference point is exogenous or at least it does not change over time. The uncertainty above which consumers refrain from lowering current consumption will depend on expectations about future interest rates and on time preferences, which are not included in a simple two period set up. 


\section{Appendix B \\ Complete estimation results}

Table B1 Ordinary least squares estimation results

(1)

\begin{tabular}{|c|c|c|c|}
\hline d1998 & $0.1576(0.0750)^{* *}$ & $0.1559(0.0751)^{* *}$ & $0.1557(0.0753)^{* *}$ \\
\hline dl995*edu & $-0.0011(0.0038)$ & $-0.0012(0.0038)$ & $-0.0009(0.0039)$ \\
\hline dl998*edu & $0.0042(0.0034)$ & $0.0042(0.0034)$ & $0.0044(0.0034)$ \\
\hline dl995*south & $0.0301(0.0386)$ & $0.0296(0.0385)$ & $0.0279(0.0385)$ \\
\hline dl998*south & $-0.0451(0.0340)$ & $-0.0427(0.0342)$ & $-0.0418(0.0342)$ \\
\hline dl995*north & $0.0667(0.0401)^{*}$ & $0.0687(0.0403)^{*}$ & $0.0658(0.0403)$ \\
\hline dl998*north & $-0.0805(0.0328)^{* *}$ & $-0.0789(0.0330)^{* *}$ & $-0.0784(0.0330)^{* *}$ \\
\hline dl995*unemp & $0.1527(0.0744)^{* *}$ & $0.1197(0.0774)$ & $0.1090(0.0764)$ \\
\hline dl998*unemp & $0.0721(0.0665)$ & $0.0422(0.0700)$ & $0.0432(0.0701)$ \\
\hline dl995*self & $-0.0050(0.0350)$ & $-0.0087(0.0354)$ & $-0.0102(0.0356)$ \\
\hline dl998*self & $0.0134(0.0302)$ & $0.0123(0.0303)$ & $0.0117(0.0303)$ \\
\hline dlncomp & $0.2482(0.0689)^{* * *}$ & $0.2467(0.0692)^{* * *}$ & $0.2454(0.0694)^{* * *}$ \\
\hline age & $-0.0022(0.0011)^{* *}$ & $-0.0022(0.0011)^{* *}$ & $-0.0022(0.0011)^{* *}$ \\
\hline lagwwife & $0.0011(0.0190)$ & $0.0008(0.0191)$ & $0.0023(0.0191)$ \\
\hline diff-married & $0.0677(0.0921)$ & $0.0673(0.0925)$ & $0.0656(0.0928)$ \\
\hline $\operatorname{Var}[\Delta \ln Y]$ & $-2.08 \mathrm{e}-09(2.61 \mathrm{e}-09)$ & $-3.16 e-09(2.63 e-09)$ & $-8.93 e-08(7.00 e-08)$ \\
\hline$\Delta \ln E[Y]$ & $-0.0057(0.0070)$ & & \\
\hline$\Delta \ln E[Y]^{+}$ & & $0.0030(0.0090)$ & $0.0094(0.0105)$ \\
\hline$\Delta \ln E[Y]^{-}$ & & $0.0108(0.0096)$ & $0.0109(0.0096)$ \\
\hline $\operatorname{Var}[\Delta \ln \boldsymbol{Y}]^{*} \Delta \ln E[Y]^{-}$ & & & $0.3376(0.8105)$ \\
\hline $\operatorname{Var}[\Delta \ln Y]^{*} \Delta \ln E[Y]^{+}$ & & & $8.76 \mathrm{e}-09$ (7.07e-09) \\
\hline
\end{tabular}

Notes: OLS estimation of the Euler equation (14). lagwwife is a dummy indicating the lagged working status of the spouse, age is household head age, dlncomp the log-difference in the number of family components, diff-married is the difference between married status dummies at time $t+1$ and $t$. Year dummies, their interactions with years of education $(e d u)$, macroregions (north, south), unemployment (unemp), and self-employment dummies (self) account for exogenous shocks. Column (1) includes among the regressors $\operatorname{Var}[\Delta \ln C]$ and $\Delta \ln \mathrm{E}[Y]$. In column (2) $\Delta \ln \mathrm{E}[Y]$ is replaced by $\Delta \ln \mathrm{E}[Y]^{+}$and $\Delta \ln \mathrm{E}[Y]^{-}$. In Column (3) interactions among expected income variance and expected income growth and decline are added. Robust standard errors are presented in parenthesis. ${ }^{\star}$ Significant at $10 \%$; ${ }^{* *}$ significant at $5 \% ;{ }^{* *}$ significant at $1 \%$. 
Table B2 2SLS estimation: first stage

dep variable: $\Delta \ln Y$

$\begin{array}{lc}\text { dl998 } & 0.2369(0.4910) \\ \text { dl995*edu } & 0.0447(0.0255)^{*} \\ \text { dl998*edu } & 0.0409(0.0253) \\ \text { dl995*south } & -0.6514(0.3182)^{* *} \\ \text { dl998*south } & -0.1344(0.2454) \\ \text { dl995*north } & 0.0671(0.2718) \\ \text { dl998*north } & -0.2056(0.2251) \\ \text { dl995*unemp } & 0.6441(0.7975) \\ \text { dl998*unemp } & 2.4205(0.6982)^{* * *} \\ \text { dl995*self } & 0.3444(0.2719) \\ \text { dl998*self } & 0.1017(0.1981) \\ \text { dlncomp } & 0.3020(0.6600) \\ \text { age } & -0.0638(0.0109)^{* * *} \\ \text { lagwwife } & 0.2754(0.1484)^{*} \\ \text { diff-married } & 0.1197(0.4396) \\ \text { Var [ } \Delta \text { In } Y] & 1.47 e-08(3.05 e-08) \\ \Delta \text { In E[Y] } & 0.3934(0.0673)^{* * *}\end{array}$

Notes: First stage regression on the 2SLS estimation. Demographics and controls for exogenous shocks are the same as in Table B1. $\Delta \ln \mathrm{E}[Y]$ is the excluded instrument. Robust standard errors are presented in parenthesis. ${ }^{\star}$ Significant at $10 \%$; ${ }^{\star *}$ significant at $5 \%$; ${ }^{* * *}$ significant at $1 \%$. 
Table B3 2SLS estimation: second stage

(1)

\begin{tabular}{l}
\hline dl998 \\
dl995*edu \\
dl998*edu \\
dl995*south \\
dl998* south \\
dl995*north \\
dl998*north \\
dl995*unemp \\
dl998*unemp \\
dl995*self \\
dl998*self \\
dlncomp \\
age \\
lagwwife \\
diff-married \\
Var[ $[\Delta \ln Y]$ \\
$\Delta \ln E[Y]$ \\
$\Delta \ln E[Y]^{+}$ \\
$\Delta \ln E[Y]^{-}$ \\
$\operatorname{Var}[\Delta \ln Y]^{*} \Delta \ln E[Y]^{-}$ \\
$\operatorname{Var}[\Delta \ln Y]^{*} \Delta \ln E[Y]^{+}$
\end{tabular}

(2)

(3)

$$
\begin{gathered}
0.1681(0.0727)^{* *} \\
0.0009(0.0038) \\
0.0051(0.0035) \\
0.0088(0.0431) \\
-0.0446(0.0337) \\
0.0602(0.0403) \\
-0.0816(0.0333)^{* *} \\
0.1942(0.0842)^{* *} \\
0.1069(0.1123) \\
-0.0001(0.0354) \\
0.0138(0.0300) \\
0.2574(0.0673)^{* * *} \\
-0.0035(0.0017)^{* *} \\
0.0095(0.0189) \\
0.0638(0.0922) \\
-1.49 \mathrm{e}-08(1.61 \mathrm{e}-08) \\
-0.0182(0.0238) \\
0.0150(0.0208) \\
0.2954(0.1438)^{* *} \\
2.54 \mathrm{e}-09(3.29 \mathrm{e}-09)
\end{gathered}
$$

Notes: 2SLS estimation of the Euler equation (14). Demographics and controls for exogenous shocks are the same as in Tables B1 and B2. Column (1) includes among the regressors $\operatorname{Var}[\Delta \ln C]$ and $\Delta \ln \mathrm{E}[Y]$. In column (2) $\Delta \ln \mathrm{E}[Y]$ is replaced by $\Delta \ln \mathrm{E}[Y]^{+}$and $\Delta \ln \mathrm{E}[Y]^{-}$. In Column (3) interactions among expected income variance and expected income growth and decline are added. Actual income growth is instrumented with expected income growth. First stage regression is reported in Table B2. Predicted income decline and increase in columns (2) and (3) are obtained as explained in Section 4. Bootstrapped standard errors (1000 replications) are presented in parenthesis. ${ }^{\star}$ Significant at $10 \%$; ${ }^{*}$ significant at $5 \%$; ${ }^{* * *}$ significant at $1 \%$. 
Table B4 Marginal effects for expected income

\begin{tabular}{|c|c|c|c|}
\hline $\begin{array}{l}\operatorname{Var}\left(\Delta \ln Y_{t+1}\right) \\
\text { percentile }\end{array}$ & $\varphi^{+}$ & $\varphi^{-}$ & $\begin{array}{l}\text { t-stat for } H_{0,2}: \\
H_{0}: \varphi^{-}-\varphi^{+}=0 \text { versus } \\
H_{1}: \varphi^{-}-\varphi^{+}>0\end{array}$ \\
\hline 5 & $-0.0182(0.0238)$ & $0.015(0.0208)$ & 1.0507 \\
\hline 10 & $-0.0182(0.0238)$ & $0.015(0.0208)$ & 1.0507 \\
\hline 15 & $-0.0182(0.0238)$ & $0.015(0.0208)$ & 1.0509 \\
\hline 20 & $-0.0182(0.0238)$ & $0.015(0.0208)$ & 1.0512 \\
\hline 25 & $-0.0182(0.0238)$ & $0.015(0.0208)$ & 1.0519 \\
\hline 30 & $-0.0182(0.0238)$ & $0.015(0.0208)$ & 1.0529 \\
\hline 35 & $-0.0182(0.0238)$ & $0.0151(0.0208)$ & 1.0541 \\
\hline 40 & $-0.0182(0.0238)$ & $0.0151(0.0208)$ & 1.0565 \\
\hline 45 & $-0.0182(0.0238)$ & $0.0152(0.0208)$ & 1.0598 \\
\hline 50 & $-0.0182(0.0238)$ & $0.0154(0.0208)$ & 1.0635 \\
\hline 55 & $-0.0182(0.0238)$ & $0.0156(0.0208)$ & 1.0721 \\
\hline 60 & $-0.0182(0.0238)$ & $0.0163(0.0208)$ & 1.0920 \\
\hline 65 & $-0.0182(0.0238)$ & $0.0178(0.0209)$ & 1.1391 \\
\hline 70 & $-0.0182(0.0238)$ & $0.0235(0.0214)$ & $1.3061 *$ \\
\hline 75 & $-0.0182(0.0238)$ & $0.0328(0.0228)$ & $1.5494^{*}$ \\
\hline 80 & $-0.0182(0.0238)$ & $0.0378(0.0239)$ & $1.6607^{* *}$ \\
\hline 85 & $-0.0182(0.0238)$ & $0.042(0.025)^{*}$ & $1.7452^{* *}$ \\
\hline 90 & $-0.0182(0.0238)$ & $0.05(0.0274)^{*}$ & $1.8819 * *$ \\
\hline 95 & $-0.0182(0.0238)$ & $0.0977(0.046)^{* *}$ & $2.2393 * *$ \\
\hline
\end{tabular}

Notes: Each line report the marginal effect of expected income increase $\varphi^{+}$, the marginal effect of expected income decline $\varphi^{+}, t$-statistic for test $H_{0,2}: \varphi^{+}<\varphi^{-}$for a given percentile of expected income variance. $\varphi^{+}$is almost constant across the whole distribution: difference across percentile are not larger than $10^{-8}$ and therefore are not highlighted in the table. ${ }^{\star}$ Significant at $10 \%$; ${ }^{*}$ significant at $5 \% ;{ }^{* *}$ significant at $1 \%$. 